\title{
CAATINGA DO CARIRI PARAIBANO
}

\author{
Jose Jakson Amâncio Alves
}

\begin{abstract}
RESUMO
A caatinga se constitui num ecossistema extremamente adaptado às condições de aridez, com um notável potencial de regeneração, porém, seus mecanismos de autodefesa tornam-se consideravelmente vulneráveis as condições que lhes são impostas. Os processos morfoclimáticos típicos do meio semi-árido, com suas estações contrastadas e as degradações antrópicas, são responsáveis por um dinamismo da vegetação em que a caatinga raquítica e rala representa um sub-clímax e a caatinga em fase de regeneração são disclimax antrópicos. A caatinga arbórea ou floresta seca seria, neste caso, o verdadeiro clímax mesmo atingido pelas ações antrópicas. A partir desse pressuposto objetivou-se nesse estudo estabelecer uma classificação provisória baseada na pressão antrópica e descrever fitogeograficamente a caatinga da região do Cariri Paraibano, onde apesar das características de pobreza do estrato herbáceo é rica em espécies e em biomassa. Também é importante considerar o processo de ocupação da região, os desmatamentos indiscriminados, associados à fragilidade natural desse ecossistema, que acarretaram sérias conseqüências para os geótopos e para as biocenoses, dentre estas a redução da diversidade biológica da vegetação nativa, produzindo uma diversidade de extratos, apresentada nesse trabalho como comunidade-tipo.

Palavras-chaves: Vegetação Nativa; Fitogeografia; Comunidade-Tipo; Semi-Árido.
\end{abstract}

\begin{abstract}
The Caatinga biome is an ecosystem are adapted to extremely arid conditions, with a remarkable potential for regeneration, but its mechanisms of self-defense become far more vulnerable to conditions imposed on them. The typical morphoclimatic processes of the semi-arid environment, with its contrasting seasons and anthropogenic degradation, are responsible for the dynamism of vegetation in the Caatinga is a rickety thin sub-climax Caatinga in the process of regeneration is a anthropic disclimax. Tree caatinga or dry forest tree would, in this case, the true climax even reached by human actions. From this assumption objective of this study is to establish a provisional classification based on human disturbance, to describe the phytogeography of the Caatinga of Cariri of the Paraiba State (NW region of Brazil), where despite the poverty characteristics of the herb is rich in species and biomass. It is also important to consider the process of occupation of the region, the indiscriminate deforestation, coupled with the weakness of natural ecosystem, which led to serious consequences for geotope and the aquatic communities, among them the reduction of biological diversity of native vegetation, producing a variety of extracts, presented in this work as a community type.

Keywords: Native Vegetation; Fitogeography; Community-Kind; Semi-Arid.
\end{abstract}

\section{INTRODUÇÃO}

O Estado da Paraíba é subdividido em três regiões climáticas, a saber: a fachada atlântica tropical aliseana e úmida; a superfície do planalto da Borborema, onde se situam os Cariris, com seu clima semi-árido acentuado; e o Sertão, duas vezes mais chuvoso do que os Cariris, também, na faixa semi-árida. Na Paraíba, os Cariris formam uma diagonal Nordeste-Sudoeste (NE-SW) que pode ser cognominar de diagonal seca. Esses aspectos climatológicos tornam a caatinga uma formação complexa do ponto de vista espacial, onde sua fisionomia varia bastante dentro do semi-árido Nordestino, o que resulta na configuração espacial de comunidade-tipo na caatinga.

$\mathrm{Na}$ Paraíba dentro das três regiões climáticas, espécies da caatinga aparecem em comunidade-tipo, variando de agreste (zona de transição) ao sertão. Ao observarmos o comportamento geoecológico das caatingas, vemos de imediato que esta, na realidade, é um mosaico de diferentes formações reunidas pelas mais variadas transições.
Isto causa muitos problemas para enquadrá-la em uma classificação universal, uma vez que a maioria de seus aspectos fisionômicos é decorrente da interrelação complexa entre fatores ecológicos (clima, topoclima, condições edáficas e topográficas) e fatores antrópicos.

Contudo a caatinga representa uma das formações vegetais mais estudadas por pesquisadores estrangeiros e brasileiros. Muitas publicações expõem suas características florísticas, estruturais, fisionômicas e o seu dinamismo.

Alguns desses trabalhos, afirmam que todas as formas da caatinga atual são oriundas da degradação antrópica, sendo o clímax a floresta seca. Para outros, sem negar o papel das ações humanas diretas e indiretas, consideram as florestas secas, a caatinga arbustivas e as estepes como formações clímax, sendo estas de ordem mesoclimáticas ou edáficas.

Dentre os que consideram a ação antrópica como um fator influenciador dos fácies que a caatinga apresenta podem ser citados: Luetzelbourg (1922), Vasconcelos Sobrinho (1978), Andrade-Lima (1971; 1973; 1981), 
Hayashi (1976; 1988), Aubréville (1961; 1965), Melo (1983; 1998), Alves (2007; 2008) e Nascimento \& Alves (2008a; 2008b).

Schnell (1961), Foury (1982), citando dois dos mais ilustres, entre tantos outros pesquisadores, afirmam que os parâmetros climáticos e edáficos são os maiores responsáveis pelos diferentes aspectos fisionômicos da caatinga, mas que os fatores antrópicos devem ser considerados na sua diversidade.

Mas recentemente, Alves $(2007,2008)$ e Nascimento \& Alves (2008a) que estudou a caatinga do semi-árido paraibano, afirmam que a floresta seca, com suas diferentes formas, seria a formação primitiva de onde, por degradação teriam originado a caatinga.

Entende-se assim, que as conseqüências dos impactos ambientais negativos das atividades humanas como fogo, a pecuária extensiva, o sistema agrícola e extrativismo vegetal estariam na origem dessas transformações. Atualmente, afirmam esses autores, que a reconstituição da floresta primitiva raramente é possível por diversas razões: desaparecimento do ambiente microclimático do sub-bosque, que permitiria a vida e a regeneração das espécies florestais; extrema lentidão do crescimento das espécies lenhosas; degradação dos solos e das condições hídricas em conseqüência dos desmatamentos.

Citam ainda que poucas espécies sejam capazes de se adaptar a estas novas condições e o caráter secundário da caatinga, explicando desse modo, a pobreza e homogeneidade dessa formação que, no seu estado atual, seria relativamente recente. Mesmo assim, Hayashi (1988) identificaram sete formas de crescimento ou de formas biológicas na caatinga. Elas se combinam e dão origem a nove tipos fisionômicos. Para estes autores, estes tipos refletem fatores climáticos, edáficos e antrópicos. Assim sendo, se os impactos ambientais das atividades humana, positivos ou negativos, não forem muito significativos, os dois primeiros assumem o papel determinante nos aspectos fisionômicos, estruturais e florísticas da caatinga, que também, é uma vegetação secundaria originada a partir de uma formação primitiva, a floresta seca.

\section{MATERIAIS E MÉTODOS}

\section{Área de Estudo}

Os Cariris formam uma saliência voltada para o Sudoeste do Planalto da Borborema na Paraíba. Seus limites passam ao Sul do eixo rodoviário da BR-230 e suas vias de acesso se situam entre Queimadas e Boqueirão, a Leste, Soledade ao Norte, e o vale do rio Farinha a Noroeste. Ao Sul, a Oeste e Sudeste, a superfície dos Cariris é cercada pelas serras elevadas que formam um arco montanhoso e assinalam a fronteira com o estado de Pernambuco: de Oeste para o Sul (Serra dos Cariris Velhos, do Mulungu, das Porteiras, da Jararaca, etc.) e daí para Sudeste (Serra da Quebrada, Serra da Cachoeira).

O Cariri (Figura 1) é uma microrregião do Estado da Paraíba localizada na franja ocidental do planalto da Borborema. Composta por 29 municípios, ocupa uma área de $11.233 \mathrm{~km}^{2} \mathrm{e}$, segundo o censo do IBGE

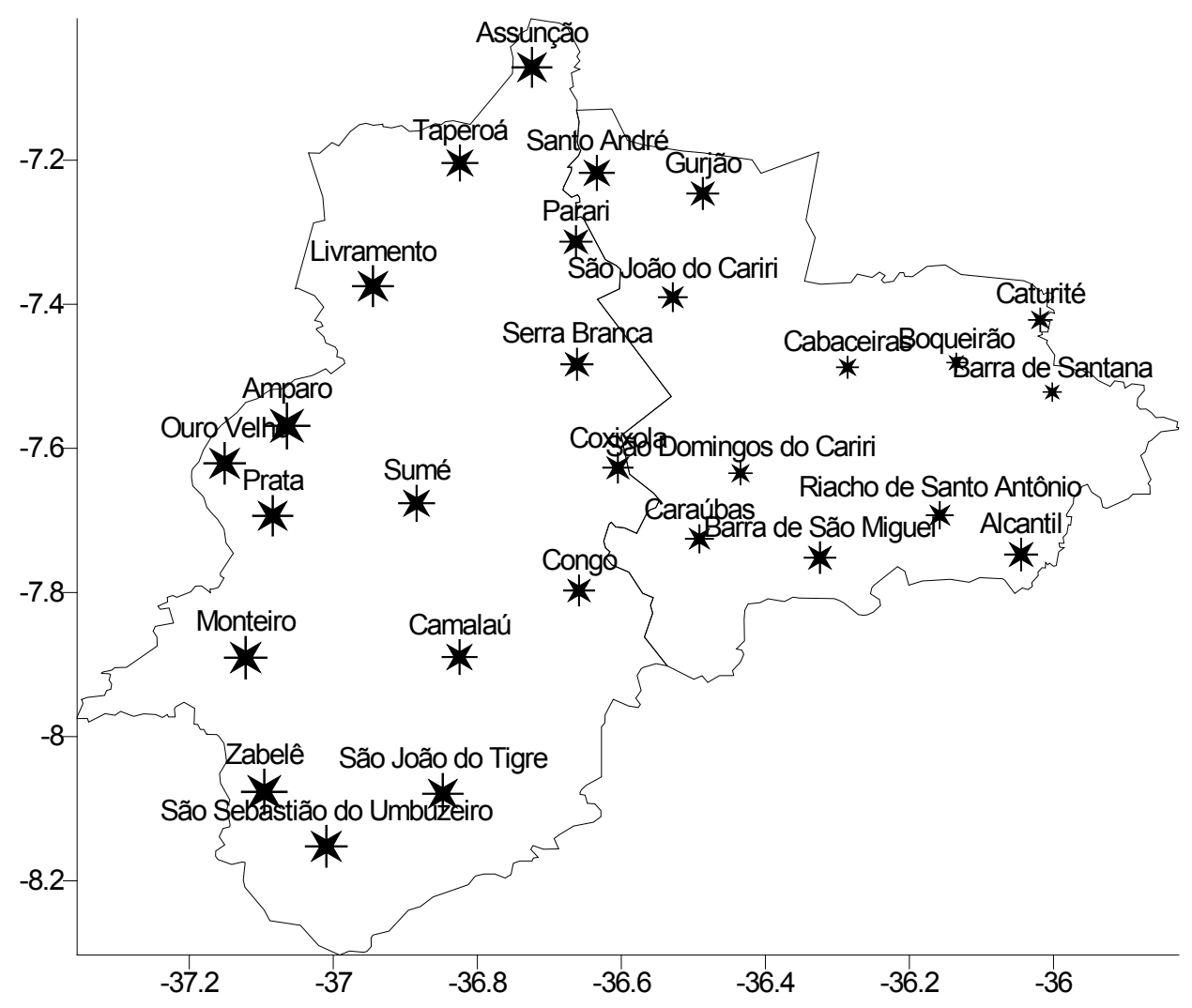

Figura 1 - Espacialidade das cidades na região dos Cariris paraibano.

Fonte: Nascimento \& Alves, 2008 a. 
de 2000, possui uma população de 173.323 habitantes, apresentando uma densidade demográfica de 15,65 habitantes por $\mathrm{km}^{2}$ (Cantalice, 2006).

Localizada em plena "diagonal seca", onde se observam os menores índices de precipitação pluviométrica do semi-árido brasileiro, com médias anuais históricas inferiores a $400 \mathrm{~mm}$ (Cohen \& Duqué, 2001), seu clima regional (Bsh) caracteriza-se por elevadas temperaturas (médias anuais em torno de $26^{\circ} \mathrm{C}$ ), fracas amplitudes térmicas anuais e chuvas escassas, muito concentradas no tempo e irregulares (Nascimento \& Alves, 2008a).

Dentre os elementos comuns de sua paisagem já citados, predominam: (i) os baixos índices pluviométricos, (ii) a caatinga hiperxerófila, (iii) as limitações edáficas, (iv) cidades pequenas com baixa densidade demográfica, (v) e uma economia baseada na agropecuária extensiva, principalmente o gado caprino. No Cariri, apesar da altitude superior a $300 \mathrm{~m}$, prevalece a feição de pediplano de superfície irregular, embutido na superfície de aplainamento do planalto da Borborema. Nesse caso, constitui-se numa área rebaixada pela ação das águas da bacia hidrográfica do rio Paraíba, cortado ocasionalmente por relevos residuais, ora isolados, ora em alinhamentos (Nascimento \& Alves, 2008b).

Quanto ao aspecto climático dominante, o Cariri encontra-se localizado no fim do percurso dos fluxos úmidos que se direcionam para o semi-árido nordestino e em situação de sotavento, fazendo parte da diagonal mais seca do Brasil, onde é comum, em determinado setores, o registro pluviométrico médio anual inferior a $300 \mathrm{~mm}$. Além disso, essas precipitações apresentam elevada variabilidade, não apenas a nível anual, mas também, dentro dos próprios meses considerados chuvosos (fevereiro a maio).

Dessa maneira, conforme o que observou Nimer (1980), as variações pluviométricas e a instabilidade climática acabam refletindo para a região as piores condições relativas ás ações auto-reguladoras e de autodefesa ambiental das comunidade-tipo da caatinga. Por isso, essa região é considerado um dos pólos xéricos do Nordeste Brasileiro; pela precipitação média anual que não atingi $600 \mathrm{~mm}$, alcançando em Cabaceiras 246 $\mathrm{mm}$ sendo o de mais baixo índice pluviométrico do Brasil (Moreira, 1997).

A temperatura média anual é $26^{\circ} \mathrm{C}$, com médias mínimas inferiores a $20^{\circ} \mathrm{C}$, e a umidade relativa do ar não ultrapassa $75 \%$ (Barbosa, et al. 2007). A pluviosidade reduzida e o relevo, basicamente em duas unidades, terrenos dissecados e no nível da Borborema, condicionam a diversidade e riqueza da vegetação. No Cariri os solos são rasos e pedregosos e a vegetação é considerada baixa e pobre em espécies, mas acompanha um gradiente de precipitação e profundidade do solo (Sampaio et al. 1981).

Sobre a vegetação, Gomes (1979) analisando os padrões de caatinga no Cariri, observou que a precipitação foi o principal fator ambiental condicionante das diferenças encontradas na vegetação; desde comunidades de menor densidade até as de maiores porte, mudando gradativamente. Esta ordenação está correlacionada principalmente com a precipitação média anual e com as características de altura e densidade das espécies encontradas, não apresentando correlação com os diferentes tipos de solo observados (Barbosa, et al. 2007). Para Andrade-Lima (1981) ocorre uma unidade própria em relação à vegetação no Cariri Paraibano, considerando a associação Caesalpinia-Aspidosperma como típica desta região.

\section{Método}

Com relação a uma metodologia básica para o presente estudo, adotaram-se sucessivas pesquisas de campo, levantamento in locu, seguido de levantamentos de dados e analise através de fotos e outros registros (oral etc.). Entende-se por comunidade-tipo espécies que caracterizam uma associação vegetal relacionada ao clima e o solo (Andrade-Lima, 1981), ou seja, as características edafoclimatológicas de determinado lugar.

Os trabalhos de campo foram essenciais para a confirmação de dados obtidos em estudos de gabinete. Com o referido conhecimento do grau de diversidade das unidades geoecológicas (comunidade-tipo) delimitadas (caatingas do Cariri) espera-se contribuir e tornar reconhecido uma base sólida de informações, a contribuir com futuros projetos de sustentabilidade para o meio ambiente acaatingado dos Cariris. Aplicaram-se para atingir determinado objetivo as seguintes etapas:

1. Levantamentos preliminares:

a) Recenseamento bibliográfico e cartográfico da área específica da pesquisa.

b) Exame conjugado das cartas topográficas e fotografias visando:

Levantamento das áreas comunidade-tipo de caatinga;

Identificação das áreas onde ocorrem ou ocorreram caatingas diferenciadas;

2. Levantamentos de campo:

Análise da diversidade florística por setor in locu, caracterizando a região em termos de fisionomia da caatinga no Cariri paraibano (grau de diversidade das unidades geoecológicas delimitadas);

Definição das comunidades-tipos.

\section{RESULTADOS E DISCUSSÕES}

\author{
Comunidade-Tipo da Caatinga no Cariri \\ Paraibano
}

Em entrevistas realizadas junto a comerciantes, lenhadores e carvoeiros em algumas cidades dos Cariris Velhos, na Paraíba, Alves \& Araújo \& Nascimento (2008) constatou que eles diferenciavam quatro tipos de caatinga, a saber:

Corresponderia à floresta densa seca, é chamada de "mata boa" e trata-se de uma caatinga arbórea que ainda conserva seus traços originais e ao que parece nunca foi derrubada;

Seria o equivalente às caatingas arbustivas e arbustivo-arbóreas densas, às quais eles chamam de 
capoeirão (trata-se de uma formação secundária que atingiu um estágio avançado de crescimento e cujas árvores têm de 4 a 5 metros de altura e o diâmetro dos troncos varia de 20 a 35 centímetros. Apresentam também algumas árvores com cerca de $10 \mathrm{~m}$ de altura);

Tipo que corresponde a uma vegetação menos desenvolvida porque mais recente - a "capoeira média" (esta é constituída de um estrato arbustivo denso, de 3 a 4 metros de altura e o diâmetro dos troncos varia de 2 a 5 centímetros. Este tipo poderia corresponder a uma caatinga arbustiva densa e baixa);

O último tipo é a forma recente, cuja idade é de menos de 3 ou 4 anos, e é dominada por pequenos arbustos dispostos em touceiras espaçadas e com altura entre 1 e 3 metros (corresponde a uma estepe com manchas de solo nu entre os tufos sub-arbustivos).

O que em síntese Alves (2007) caracterizou como sendo uma associação com predomínio de espécies lenhosas coexistindo com espécies herbáceas e gramíneas. As espécies lenhosas chamam a atenção por suas formas biológicas e pela posição dominante na estrutura da formação. Elas podem se apresentar sob a forma de árvores, de arvoretas, de arbustos e de sub-arbustos. Os arbustos e arvoretas não apresentam troncos bem desenvolvidos e são ramificados a partir do nível do solo.

Quanto às espécies herbáceas, algumas possuem ramos eretos e mais ou menos linhificados. Segundo este autor, no conjunto, a caatinga apresentam-se normalmente com porte inferior a $7 \mathrm{~m}$, embora alguns tipos possam ultrapassar esta dimensão.

Diante do estado atual de extrema devastação em que se encontram submetida às caatingas, torna-se muito difícil afirmar que o conjunto de terras semiáridas era inteiramente recoberto pela "mata branca", ou que as paisagens atuais (floresta seca, caatingas arbustivo-arbóreas e caatingas arbustivas e subarbustivas) existiam antes das ações predatórias do homem branco.

É bem possível que nenhuma dessas indagações seja totalmente verdadeira e que uma vegetação florestal tenha sempre coexistido com formações arbustivas e sub-arbustivas. Então com base na noção de "comunidade-tipo" e dos sucessivos trabalhos de campos foram possíveis estabelecer uma classificação provisória baseada em critérios fisionômico-ecológicos e tentou estabelecer uma correlação entre os índices xerotérmicos, os tipos de solo e de rochas, a pressão antrópica e a fisionomia das caatingas.

As doze comunidades-tipo podem ser facilmente reconhecidas no terreno, mas sua distribuição real no espaço ecológico é de difícil reconhecimento, pois não há limites nítidos. A passagem entre as unidades é gradual, sobretudo quando as variações são de ordem edafoclimatológica. Os doze tipos apresentados nesse trabalho estão ordenados, sobretudo em função das condições fitogeográficas. Neste caso, as mudanças entre cada um dos tipos são mais claras.
Apesar da grande devastação e da degradação que a caatinga apresenta, ainda podem ser diferenciadas formas que variam da formação mais ou menos densa e arborescente até as formações com aspectos de estepes sub-fruticosas. A prova de que a maioria dos tipos de caatinga são formações secundárias verifica-se no plano florístico: dois grupos importantes, as Mimosóideas e as Cesalpiniáceas, e em seguida, nas estações mais áridas, as Euforbiáceas e as Apocináceas, ambas no Cariri Central e Ocidental, por exemplo.

A riqueza maior ou menor em cactáceas e bromeliáceas terrestres introduz modificações no quadro morfológico e fisionômico geral. Por exemplo, as cactáceas são muito abundantes na superfície dos Cariris (550 m de altitude) entre Soledade - São João do Cariri - Juazeirinho. O mesmo ocorre com as bromeliáceas terrestres, o caroá (Neoglaziovia variegata) e a macambira-de-chão (Bromélia laciniosa), que têm ocorrência limitada ao Cariri paraibano e ao Curimataú. Os tipos identificados constam no Quadro I.

Nas serras e maciços residuais encontram-se povoamentos de pequenas árvores que formam um estrato ralo dominando um sub-bosque mais denso composto de arbustos de pequeno porte. Nas áreas aplainadas são as formações arbustivas densas espinhentas, com ou sem cactáceas, que dominam. Sobre os solos rasos e pedregosos que recobrem extensas áreas da caatinga, as formações são mais ralas e baixas; os arbustos são pequenos e dispostos em tufos afastados uns dos outros e, às vezes, com cobertura de gramíneas ou de gramíneas e herbáceas entre as Mimosóideas, Cesalpiniaceas, Euforbiáceas. Localmente, apresentam cactáceas prostradas. As espécies lenhosas têm porte raquítico. Trata-se do fácies mais seco e degradado do Cariri central (municípios de Serra Branca e São João do Cariri, entre outros, conseqüência direta da monocultura do algodão).

Por motivo de clareza e de simplificação, agrupou a caatinga observadas no campo em quatro grandes tipos:

Caatingas com povoamento lenhoso alto, mais ou menos denso, com ou sem cactáceas - Estas caatingas geralmente se situam nos relevos acidentados e apresentam normalmente: um estrato arborescente de cerca de $8 \mathrm{~m}$, podendo em alguns casos atingir $15 \mathrm{~m}$, do qual, localmente, fazem parte grandes cactáceas do gênero Cereus; um estrato arbustivo muito variado, com 2 a 4 metros, mais ou menos denso, com algumas cactáceas de pequeno porte e um tapete herbáceo anual com desenvolvimento variável segundo as condições pluviométricas anuais e edáficas, e, sobretudo, segundo a densidade dos estratos superiores se estes são suficientemente claros para permitir a penetração da luz solar; as espécies do extrato herbáceo são neste caso heliófilas.

Caatingas arbustivas com povoamento lenhoso denso, com pouca ou muita Cactáceas e Bromeliáceas - Estas são, na sua maioria, formadas de arbustos 
Quadro I - Comunidades-Tipos da caatinga do cariri Paraibano - Fonte: Elaboração Própria, 2009.

\begin{tabular}{|c|c|c|}
\hline Tipo de Caatinga & $\begin{array}{l}\text { Altura } \\
\text { Média } \\
\text { (m) }\end{array}$ & Comunidade-Tipo \\
\hline Caatinga arbórea alta & $>15$ & $\begin{array}{c}\text { Tabebuia-Aspidosperma-Astronium- } \\
\text { Cavanillesia }\end{array}$ \\
\hline Caatinga arbórea média & $7>15$ & Astronium-Schinopsis-Caesalpinia \\
\hline $\begin{array}{c}\text { Caatinga arbórea Média ou baixa } \\
\text { Densa e/ou aberta }\end{array}$ & $7>15$ & Caesalpinia-Bursera-Spondias-Aspidosperma \\
\hline Caatinga arbustiva & $5>7$ & Pilocereus-Poepiggia-Dalbergia-Piptadenia \\
\hline Caatinga arbustiva & $5>7$ & Pilocereus-Poepiggia-Dalbergia-iptadenia \\
\hline Caatinga arbórea Aberta & $5>7$ & Cnisdosculus-Bursera-Caesalpinia \\
\hline Caatinga arbustiva Baixa & $1>3$ & Caesalpinia-Aspidosperma-Jatropha \\
\hline Caatinga arbustiva aberta & $1>3$ & Caesalpinia-Aspidosperma \\
\hline Caatinga arbustiva Baixa ou alta & $1>3$ & Mimosa-Caesalpinia-Aristid \\
\hline Caatinga arbustiva Aberta baixa & $1>3$ & Aspidosperma-Pilocereu \\
\hline Caatinga arbustiva Aberta baixa & $\begin{array}{c}0,30>0,70 \\
0,50>1,0\end{array}$ & Calliandra-Pilocereus \\
\hline Florestas ripárias & $>3$ & $\begin{array}{l}\text { Copernicia-Geoffrea-Licania/ } \\
\text { Licania-Tabebuia-Bumelia }\end{array}$ \\
\hline
\end{tabular}

com altura inferior a $7 \mathrm{~m}$ e subarbustos muito ramificados desde o nível do solo, com altura variável e sem estratificação nítida. Às vezes, algumas árvores esparsas destacam-se do estrato arbustivo. Localmente, grandes cactáceas também, do gênero Cereus, que dominam o estrato arbustivo superior. Geralmente constituem a caatinga menos atingida pelos processos de desertificação local.

Caatingas mais ou menos abertas, com arbustos dispostos em touceiras esparsas e com forte densidade de Cactáceas - Trata-se de uma caatinga formada por touceiras sub-fruticosas e por maciços lenhosos separados por manchas de solo nu e afloramentos rochosos ou recobertos por tapete gramíneo-herbáceo descontinuo. O número de cactáceas de pequeno porte (baixas) é, por vezes, importante. Os maciços são geralmente constituídos por um grupo de pequenos arbustos ou por uma árvore dominando alguns arbustos que se destacam sobre tufos de plantas sub-arbustivas com 1 ou 2 metros de altura e algumas herbáceas. Esse tipo de caatinga muito freqüente caracteriza sempre os setores com aridez edáfica severa, notadamente com solos compactos e pedregosos e com grande quantidade de afloramentos rochosos, e também os setores mais degradados. A faveleira, o velame, a coroa de frade e o xique-xique caracterizam as formas mais xerófilas da caatinga. No que diz respeito à faveleira (Cnidosculus phyllacanthus) esta ocorre em duas áreas, onde se percebe neossolos. A flora do tapete de herbáceas anuais é muito variada, com exceção dos locais onde se encontra com um significativo grau de degradação ou ausente, em virtude das atividades pecuaristas.

Caatingas ralas, esparsas, baixas com aspectos estépico - Estas são formadas por pequenos arbustos dispostos em tufos esparsos e separados por grandes extensões de solo nu, ou recobertas por um tapete gramineano e herbáceo por vezes bastante desenvolvido (cerca de $70 \mathrm{~cm}$ de altura). Nos setores onde existe grande quantidade de afloramentos rochosos e solos muito pedregosos, as cactáceas prostradas do gênero Pilocereus e Opuntias e as Bromeliáceas do gênero Encholirium são muito desenvolvidas.

Diante do trabalho de campo e da fundamentação literária sobre a temática, face também, ao que foi produzido e ora aqui exposto, pode-se concluir que realmente o homem é responsável por alterações estruturais da caatinga. Elas se refletem em seu polimorfismo; mas o homem através das ações antrópicas não é o único fator. Também, querer afirmar que toda a caatinga é originada a partir das ações predatórias do homem é apenas uma das muitas hipóteses sobre os seus aspectos fisionômicos.

Condições climáticas locais, aliadas os outros fatores ecológicos como solos, fenômenos da exposição e de abrigo, características herdadas de sistemas morfoclimáticos e paleoecológicos devem ser considerados. Resta que o polimorfismo da caatinga traduz-se por diferentes fáceis, o que torna muito difícil a sua classificação. O certo é que muitos deles se devem aos fatores geotópicos, mas muitos outros trazem a marca incontestável das atividades humanas.

Ainda existem setores onde se verifica que a caatinga apresenta uns fáceis nítidos de regeneração que se caracteriza por uma sinúsia baixa, arbustiva, quase mono-específica e com ramificações baixas. Os remanescentes que foram poupados do machado e 
do fogo apresentam-se espaçados. A base de algumas dessas árvores e também dos arbustos resultam de um crescimento secundário, após terem sido cortadas.

Nos setores em que a caatinga foi transformada em pastos, seu aspecto geral é de uma savana arborizada ou não. Se as atividades cessarem, a regeneração da caatinga apresenta um grupo de arbustos com porte uniforme. As espécies de substituição são Mimosa spp., Caesalpinia spp., e Croton spp. Nos setores submetidos a uma menor pressão antrópica, a vegetação é mais densa e constituída por várias espécies cuja dominância é difícil de ser determinada.

Constata-se, nas áreas que são ocupadas por caatingas em fase de regeneração, isto é, livre das ações humanas e dos animais, a ocorrência de uma formação mais densa - o que pode ser observado pela presença de árvores poupadas e dos rebrotamentos bastante desenvolvidos a partir dos troncos cortados rente ao solo. Mas, infelizmente, quase sempre a regeneração não pode acontecer por causa da pressão humana intensa e constante. Esta, uma vez cessada, permitiria a médio ou a longo prazo, que a vegetação se reconstituísse.

Contudo tornar isso possível, é preciso considerar entre tantos fatores, em especial, os fatores ecológico tais como: localização, tipos de solo, rochas-mãe, índices pluviométricos e duração da estação seca. Não se deve esquecer também que os processos morfoclimáticos típicos do meio semi-árido, com suas estações contrastada e as degradações antrópicas, são responsáveis por um dinamismo da vegetação em que a caatinga raquíticas e ralas representa um sub-clímax e a caatinga em fase de regeneração são disclímax antrópicos. A caatinga arbórea ou floresta seca seria, neste caso, o verdadeiro clímax mesmo atingido pelas ações antrópicas.

\section{CONSIDERAÇÕES FINAIS}

Tanto as florestas secas como a caatinga estépicas hiperxerófilas seriam formas da caatinga original. Todos outros tipos são transições possíveis entre essas duas formações-clímax. A floresta seca e suas diferentes formas possíveis representariam à formação primitiva que por degradação antrópica, resultaram nas demais formas de caatinga ou comunidade-tipo, como defendido nesse trabalho.

Os desmatamentos, o super-pastoreio, as queimadas e o extrativismo estariam na origem dessas formações secundárias. O outro extremo seria representado pelas caatingas hiperxerófilas (caatingas estépicas) encontradas nas áreas mais áridas e inóspitas dos Cariris; o determinismo ambiental aliado às ações antrópicas, gera diversos tipos dessas caatingas com todas as graduações possíveis de estratos. Situação que se torna bem explícita durante a estação climática mais árida quando se agrava as condições edáficas da área, modificando toda a dinâmica fisiológica da vegetação, a qual passa a apresentar um aspecto de uma caatinga ainda mais baixa, rarefeita, com uma seleção severa das espécies.

Nas áreas onde as condições edafoclimáticas são mais favoráveis encontram-se espécies da caatinga hipoxerófila, onde os geótopos são privilegiados pela altitude e por melhores solos, a exemplo das áreas serranas, ocorrem também manhas esparsas em vales de rios e em geral onde os solos são mais profundos.

Cabe acrescentar que os Cariris é uma região fornecedora de madeira para diversas atividades econômicas na Paraíba, como é o caso da transformação da madeira em carvão, da extração de lenha para abastecer as fabricas de beneficiamento de minério, padarias, madeira, olarias e consumo doméstico. A pecuária extensiva e semi-extensiva local, com criação de bovinos, ovinos e caprinos, também é outro fator agravante para os processos de degradação da cobertura vegetal.

Neste aspecto, a sustentabilidade do bioma caatinga deve ser acompanhada de uma política de combate à degradação da cobertura vegetal considerando todos os impactos ambientais aqui citados.

\section{REFERÊNCIAS}

ALVES, J. J. A. 2007. Geoecologia da caatinga no semi-árido do Nordeste brasileiro. CLIMEP: Climatologia e Estudos da Paisagem, Rio Claro, v.2, n.1, p 58 -71.

ALVES, J.J.A.; ARAÚJO, M.A.; Nascimento, S.S. Degradação da Caatinga: uma avaliação ecogeográfica. Caminhos da Geografia. (UFU. On-line), 2008. V.9 p. 143-155.

ALVES, J. J. A. 2008. Bio_geografia. João Pessoa: Ed. Fotograf, ISBN: 978-85-904116-6-6. 108 p.

ANDRADE-LIMA. D. "A caatinga na área do pastoreio". In: Recursos Naturais, Meio Ambiente e Poluição - Contribuição para um ciclo de debates - vol. 1. Rio de Janeiro: SUPREN/ IBGE, 1971 (Série Recursos Naturais e Meio Ambiente, 2).

ANDRADE-LIMA. D. “Traços Gerais da Fitogeografia do Agreste pernambucano". In: Congresso Nacional de Botânica (Anais) p. 185-188, Recife, 1973.

ANDRADE-LIMA, D. de A. 1981. The Caatinga Dominium. Rio de Janeiro, Revisa Brasileira de Botânica, 4: 149-153 pp.

AUBRÉVILLE A. "Principes d'une systématique des formations végétales tropicales.” Adansonia 5 (2): 165-196, Paris, 1965.

AUBRÉVILLE A. 1961. Étude écologique des principales formations végétales du Brésil, et contribuition à la connaissance desforêts de l'Amazonie. Paris. p268.

BARBOSA, ET ALI. 2007. Vegetação e flora no Cariri paraibano. Ed. EDUEPB. Campina Grande. 120 p.

CANTALICE, LUCIANA RAMOS; MARTINS, MARIA DE FÁTIMA; CÂNDIDO, GESINALDO ATAÍDE. 2XXVI ENEGEP - Fortaleza, CE, Brasil. Turismo e desenvolvimento sustentável nos assentamentos da reforma agrária do cariri paraibano,2006.

COHEN, MARIANNE; DUQUE, GHISLAINE. Le deux visages du Sertão: Stratégies paysannes face aux sécheresses (Nordeste du Brésil). Paris, Éditions de L'IRD,2001. 
GOMES, M.A.F. 1979. Padrões de Caatinga nos Cariris Velhos - Paraíba. Dissertação de Mestrado. Universidade Federal de Pernambuco, Recife. 88 p.

FOURY, A. P. 1982. As Matas do Nordeste Brasileiro e sua importância econômica. Rio de Janeiro, Bol. Geog., 228:30$84 \mathrm{pp}$.

HAYASHI. I. "Changing aspect of caatinga vegetation in semiarid region Northeast Brazil". In: Agricultural land Use and Transformation of Ecosystem in the semi-arid region, Northeast Brazil. Univ. of Tsukuba. p. 61-76 (Latin American Studies, 10) 1988 .

HAYASHI. I. Communities and their environment in the caatinga of Northeast Brazil - Latin American Studies 2: 65-79, Iburahi, Japan.

LÜTZELBURG, PH. VON. Estudo Botânico do Nordeste. Rio de Janeiro: Insp. Obras Contra as Secas, 1922, 3 Vol.

NASCIMENTO, S.S.; ALVES J.J.A. Ecoclimatologia do Cariri Paraibano. Revista Geográfica Acadêmica. V. 2 n. 3 (xii, 2008). P. 28-41, 2008b. ISSN 1678-7226.

NASCIMENTO, S.S.; ALVES, J.J.A. Um Alerta Ambiental do Grau da Desertificação no Estado da Paraíba. Encontro Internacional de Geografia: Tradições e Perspectivas. Universidade de São Paulo-USP, 1 a 5 de dezembro de 2008a.
NIMER, E. 1980. Subsídio ao plano de ação mundial para combater a desertificação: programa das Nações Unidas Revista Bras. de Geografia. Rio de Janeiro, 42 (3). p. 612-637.

MELO, A. S. Tavares de. L'organisation des paysages dans l'est de la Paraiba et du Rio Grande do Norte (Brésil) - Une contribution de l'imagerie radar aux études écogéographiques. Univ. de Bordeaux III, Talence, 1983, (Tese de Doutorado).

MELO, A. S. Tavares de. "Desertificação: Etimologia, Conceitos, Causas e Indicadores". Rev. da UNIPE, João Pessoa, 2 (2):21 35, 1998.

MOREIRA, E.R. F; Targino, I. 1997. Capítulos de geografia agrária da Paraíba. João Pessoa: Editora Universitária/UFPB.

VASCONCELOS SOBRINHO, J. Metodologia para identificação de processos de desertificação: Manual de indicadores, Recife: SUDENE, 1978.

SCHNELL, R. 1961. Le problème des homologies phytogéographiques entre l'Afrique et l'Amérique tropicales. Mém. Du Mus. D’Hist. Nat., Paris. Nouv. Série XI (21), $137-$ 241 pp.

SAMPAIO, E.V.S.B.; Andrade-Lima, D; Gomes, M.A.F. 1981. O gradiente vegetacional das caatingas e áreas anexas. Revista Brasileira de Botânica, 4(1). P. 27-30. 